Original Paper

\title{
Study on Flow Fields in Variable Area Nozzles for Radial Turbines
}

\author{
Hideaki Tamaki ${ }^{1}$ and Masaru Unno ${ }^{1}$ \\ ${ }^{1}$ Turbo Machinery and Engine Technology Department \\ IHI Corporation \\ 1, Shin-nakahara-cho, Isogo-ku, Yokohama, 235-8501, Japan
}

\begin{abstract}
The flow behind the variable area nozzle which corresponds to the flow at the leading edge of the impeller was measured with a 3-hole yaw probe and calculated with CFD. Two nozzle throat-areas were investigated. One is the smallest and the other is the largest opening for the variable nozzle. Test results agreed with the calculated results qualitatively. The leakage flow through the tip clearance of the nozzle vane significantly affected the flow field downstream of the nozzle vane with the smallest opening. However, the effect on leakage flow on the flow field downstream of the nozzle vane with the largest opening was very weak and the effect of wake is dominant.
\end{abstract}

Keywords: Radial turbine, Nozzle vane, Variable geometry turbine, Clearance flow

\section{Introduction}

In order to comply with tightening emission regulations and to reduce fuel consumption, turbochargers represent a key component for Diesel engines. Variable geometry turbines are widely used to improve engine-turbocharger matching and currently common in Diesel engines. A pivoting nozzle vane moved with an actuator is especially suited to realizing optimal turbine output for the different engine operating points. Hence, the term of variable geometry turbine usually indicates the radial turbine with a pivoting nozzle vane. Hence, this paper also calls a pivoting nozzle vane to a variable area nozzle.

Several design and performance predicting methods of the variable area nozzle for radial turbines have been reported. Meitner et al. [1] proposed performance predicting methods of variable area nozzle, but they have not been verified through experiments. Many researches [2-4] were based on the stage performance of turbines and described the leakage flow from the clearance of the nozzle vane deteriorated the turbine stage performance rapidly as the nozzle vane was closing. A few researches included measurement and analysis results of detailed internal flow. Hayami et al. [5], Senoo et al. [6], and Hyun et al. [7] measured the flow field at the nozzle outlet in detail using the nozzle setting angle and clearance as parameters. However, the range of the nozzle setting angle (movable angle) for present turbochargers is much larger than that of their studies. Therefore it is necessary to understand the flow field at the nozzle outlet in a wider range of the nozzle setting angle to design turbochargers with variable area nozzles.

In this research, therefore, such nozzle setting angles as to sufficiently include the working range of the variable area nozzle of the present turbochargers were determined and flow analysis and flow measurement were conducted at the minimum opening (throat area : small, setting angle : large when measured from the radial direction, hereinafter called the smallest opening) and maximum opening (throat area : large, setting angle : small, hereinafter called the largest opening). Especially the effect of the clearance of the nozzle vane, which is indispensable to move the vane, on the flow fields at the impeller leading edge was investigated.

\section{Test Equipment and Test/Calculation Methods}

Figure 1 shows the cross section of the test equipment. The flow passing through the turbine scroll is turned and runs into the nozzle. The flow angle at the scroll outlet was designed at $67.5^{\circ}$. The flow coming out of the nozzle is turned in the axial direction and discharged into the atmosphere. The flow field at the nozzle downstream portion was measured with a 3-hole yaw probe. The measurement position was located $0.95 R_{2} . R_{2}$ is the impeller outer radius. The yaw probe could be moved in the nozzle circumferential direction with a precision slider support. The measurement was made at 7 to 9 points in the span direction (nozzle height direction, between the hub and shroud) and at 30 points, 2 degrees each, in the circumferential direction.

Figure 2 shows the shape of the nozzle cascade and definition of the vane setting angle, and Table 1 shows representative dimensions. The throat width is a relative value with the largest opening as 1.0, and the measuring positions for the nozzle trailing edge and nozzle outlet diameter are shown in the ratio to the diameter of the nozzle rotation center, the position of the pivot. The

Received July 25 2008; revised August 11 2008; accepted for publication August 17 2008: Review conducted by Prof. Youn-Jea Kim. Corresponding author: Hideaki Tamaki, hideaki_tamaki@ihi.co.jp 
throat width of the largest opening is $12.44 \mathrm{~mm}$ and the diameter of the nozzle rotation center is $111.35 \mathrm{~mm}$. The number of the nozzle vanes is 11 . In the test, a non-rotational flow channel was used in place of the turbine impeller, and so it was difficult to determine if the nozzle test conditions corresponded to the operating points of the turbine. In understanding the nozzle general internal flow pattern, however, the effect of the nozzle test conditions would not be significant. Table 2 shows the test conditions and calculation points. To check the effect of the clearance, the nozzle vanes with clearance and without clearance on the shroud side were used. In this research, the value of clearance was made 2.5 times that of the normal variable nozzle to clarify the effect of the clearance. In this paper, the pressure side and suction side are defined as shown in Fig. 2. Appendix-1 explains the definition of pressure and suction surface.

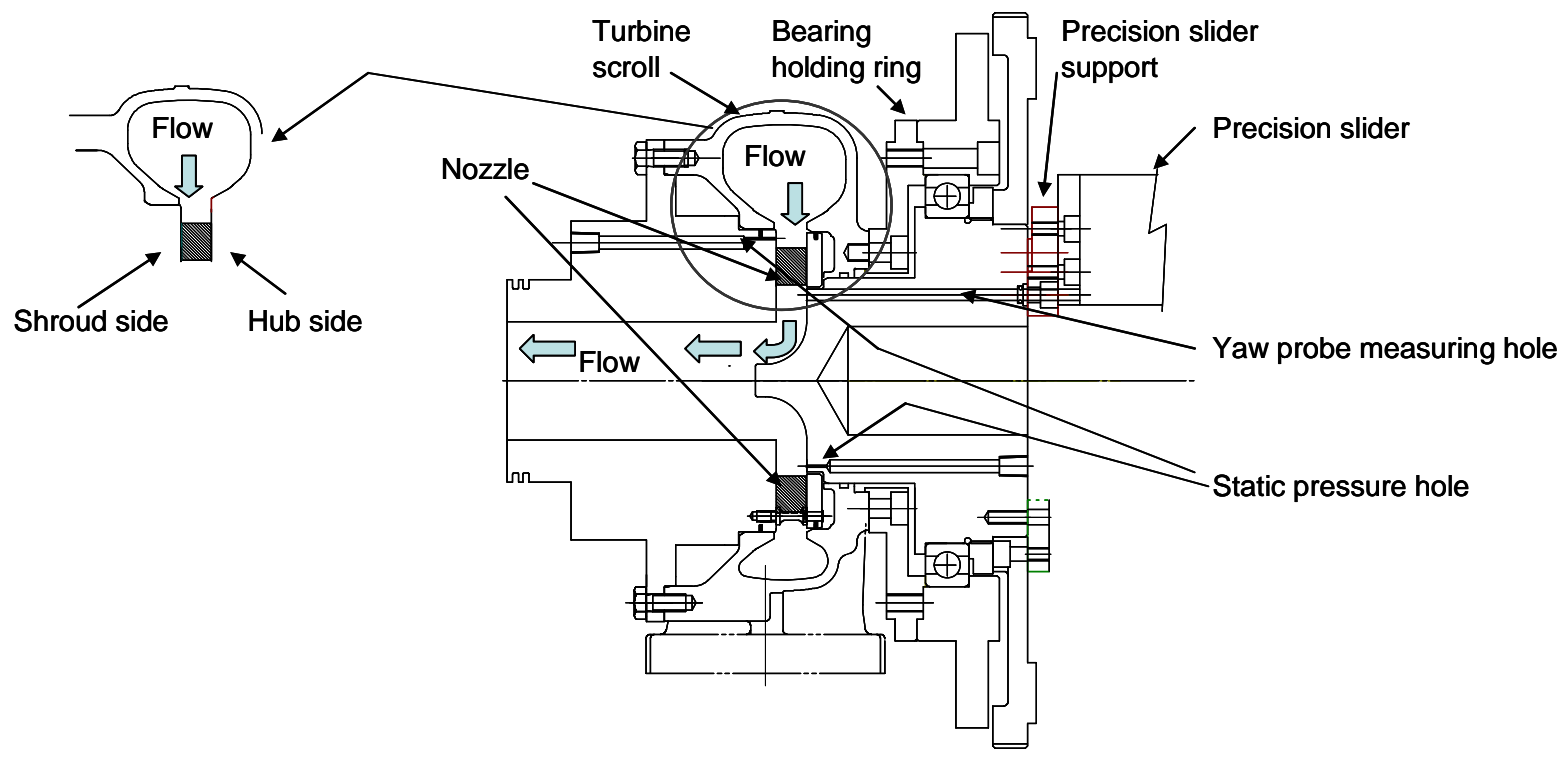

Fig. 1 Test rig

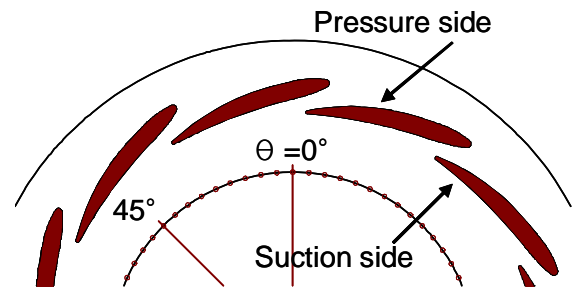

(a) Smallest opening

Fig. 2 Tested nozzles

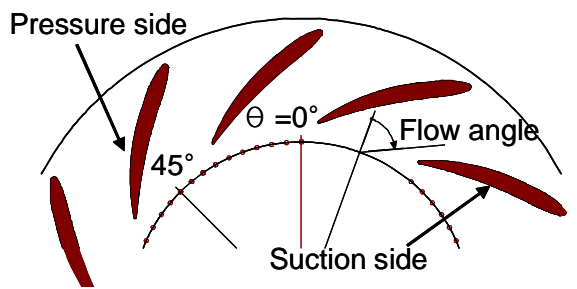

(b) Largest opening

Table 1 Nozzle main dimension

\begin{tabular}{|c|c|c|c|c|c|c|c|}
\hline Item & $\begin{array}{l}\text { Inlet } \\
\text { angle } \\
\text { (deg.) }\end{array}$ & $\begin{array}{l}\text { Outlet } \\
\text { angle } \\
\text { (deg.) }\end{array}$ & $\begin{array}{l}\text { Vane } \\
\text { height } \\
(\mathrm{mm})\end{array}$ & $\begin{array}{c}\text { Nozzle } \\
\text { clearance } \\
(\mathrm{mm})\end{array}$ & $\begin{array}{c}\text { Throat } \\
\text { width } \\
(-)\end{array}$ & $\begin{array}{c}\text { Position nozzle } \\
\text { trailing edge } \\
(-)\end{array}$ & $\begin{array}{c}\text { Measuring } \\
\text { position } \\
(-)\end{array}$ \\
\hline \multirow{2}{*}{$\begin{array}{l}\text { Smallest } \\
\text { opening }\end{array}$} & \multirow{2}{*}{72.0} & \multirow{2}{*}{85.0} & 12.75 & 0.75 & \multirow{2}{*}{0.27} & \multirow{2}{*}{0.94} & \multirow{4}{*}{0.71} \\
\hline & & & 13.50 & 0.0 & & & \\
\hline \multirow{2}{*}{$\begin{array}{l}\text { Largest } \\
\text { opening }\end{array}$} & \multirow{2}{*}{51.0} & \multirow{2}{*}{65.0} & 12.75 & 0.75 & \multirow{2}{*}{1.0} & \multirow{2}{*}{0.79} & \\
\hline & & & 13.50 & 0.0 & & & \\
\hline
\end{tabular}

Table 2 Test conditions and CFD results

\begin{tabular}{c|c|c|c|c|c|c}
\hline \hline \multirow{2}{*}{$\begin{array}{c}\text { Item } \\
\text { Nozzle vane }\end{array}$} & $\begin{array}{c}\text { Vane height } \\
(\mathrm{mm})\end{array}$ & $\begin{array}{c}\text { Clearance } \\
(\mathrm{mm})\end{array}$ & & \multicolumn{2}{|c|}{ Test conditions } & \multicolumn{2}{c}{ CFD results } \\
\cline { 3 - 7 } & & & $\mathrm{GT}_{0}{ }^{0.5} / \mathrm{P}_{0}$ & $\begin{array}{c}\mathrm{P}_{\mathrm{LE}} / \mathrm{P}_{\mathrm{TE}} \\
(-)\end{array}$ & $\mathrm{GT}_{0}{ }^{0.5} / \mathrm{P}_{0}$ & $\begin{array}{c}\mathrm{P}_{\mathrm{LE}} / \mathrm{P}_{\mathrm{TE}} \\
(-)\end{array}$ \\
\hline $\begin{array}{c}\text { Smallest } \\
\text { opening }\end{array}$ & 12.75 & 0.75 & $1.83 \times 10^{-5}$ & 1.30 & $1.81 \times 10^{-5}$ & 1.30 \\
\hline $\begin{array}{c}\text { Largest } \\
\text { Opening }\end{array}$ & 13.50 & 0.0 & $1.31 \times 10^{-5}$ & 1.30 & $1.36 \times 10^{-5}$ & 1.32 \\
\cline { 2 - 7 }
\end{tabular}

(Note) $\mathrm{G}$ : Mass Flow Rate $(\mathrm{kg} / \mathrm{s}) \quad \mathrm{P}_{\mathrm{LE}}$ : Static pressure at nozzle inlet $(\mathrm{Pa})$

$\mathrm{T}_{0}$ : Inlet Total Temperature $(\mathrm{K})$

$\mathrm{P}_{\mathrm{TE}}$ : Static pressure at nozzle outlet $(\mathrm{Pa}) \mathrm{P}_{0}$ : Inlet Total Pressure $(\mathrm{Pa})$ 


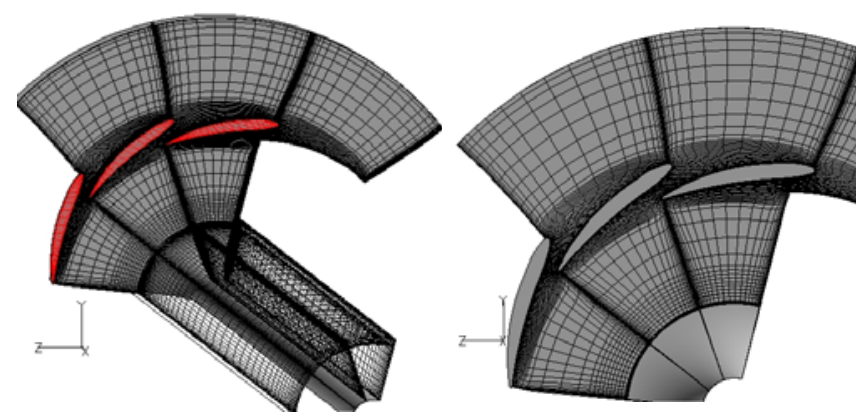

Fig. 3 Computational grid

Figure 3 shows the computational grid. The calculation was made on the nozzle vane with clearance. For the vane portion, H$\mathrm{H}$ type structural grids were arranged at 69 points in the span direction (including 20 points within the clearance), 57 points in the circumferential direction, and 69 points in the flow direction (233 points in total). For the calculation the code developed by IHI was applied. For the convective term, the Chakravarthy-Osher TVD scheme was used, and for the turbulence, the SpalartAllmaras model was used. As boundary conditions, total pressure, total temperature, and flow angle were fixed at the inlet boundary. The test value for the total temperature and the scroll outlet flow angle (design value) for the flow angle were used at the inlet boundary. At the outlet boundary, the static pressure was fixed to the atmospheric pressure, and the periodic boundary condition was used. The inlet total pressure was adjusted so that the static pressure ratio before and after the nozzle almost equaled the test value.

\section{Test and Calculation Results}

Figure 4 and Fig. 5 show the calculation results of the smallest and largest openings of the nozzle vane. $\mathrm{c}$ and $\mathrm{x}$ are the chord length and distance from the nozzle vane leading edge respectively. The static pressure (Ps) distribution on the vane shows the values of the mid-span and is made dimensionless at the scroll inlet total pressure ( $\mathrm{P} 0)$. The limiting stream line is at the shroud side. Figure 6 shows the results of oil flow visualization. The Mach number distribution is that of the mid-span portion.

In case of the smallest opening (Fig. 4), the flow has a positive incidence against the nozzle vane, and the pressure on the pressure side is higher than that on the suction side. At the overlap portion of the pressure side and suction side, a passage similar to a channel with rectangle cross-section is formed, and in case of the smallest opening, the length of this passage is short. For this reason, the flow velocity on the pressure side is low over the entire nozzle vane, and the pressure on the pressure side is higher than on the suction side. Due to this pressure difference, the leakage flow of the clearance portion goes towards the suction side from the pressure side. This leakage flow spreads in the nozzle while forming a tip leakage vortex due to the pressure gradient from the outer radius to the inner radius of the nozzle. The limiting streamline is almost the same as the oil flow visualization. Visualization confirms that the tip leakage flow discharging from the pressure side to the suction side on the shroud wall side with clearance rolls up in the main flow and converges into the tip leakage vortex. On the other hand, the flow on the hub side without clearance smoothly increases in velocity. The region, where the density of the limiting streamline is low and is shape like a cigar, appears. This region corresponds to the trace of the tip leakage vortex near the shroud wall.

In case of the largest opening (Fig. 5), the flow has a negative incidence against the nozzle vane, and the pressure on the suction side of the nozzle vane is higher than on the pressure side. On the suction side, development of a low speed area is observed due to the effect of the negative incidence, and at the latter half portion, the difference in pressure between the suction side and pressure side decreases. The leakage flow passing the clearance due to the pressure difference between the suction side and pressure side goes to the pressure side from the suction side. This leakage flow is restrained to the pressure side due to the pressure gradient towards the inner radius from the outer radius of the nozzle and flows out while forming a tip leakage vortex along the nozzle pressure surface. The limiting streamline is similar to the oil flow visualization. The limiting streamline and visualization reveal that the vane shape appears on the shroud wall side with a clearance. The reason is considered to be that the leakage flow is limited between the edge of the nozzle vane and the shroud wall. In case of the largest opening, it is predicted that the effect of the leakage vortex on the flow field on the nozzle is limited. Visualization shows that separation occurs on the pressure side at the hub side. This separation reaches between the nozzle vanes.

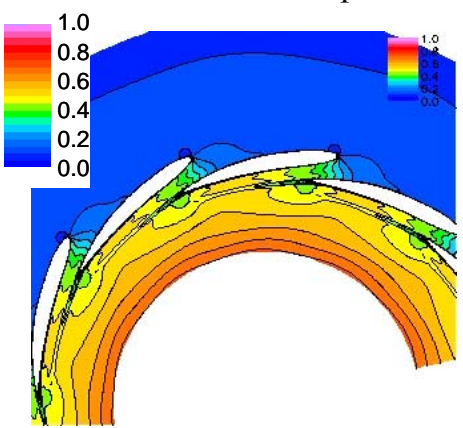

(a) Mach number distribution

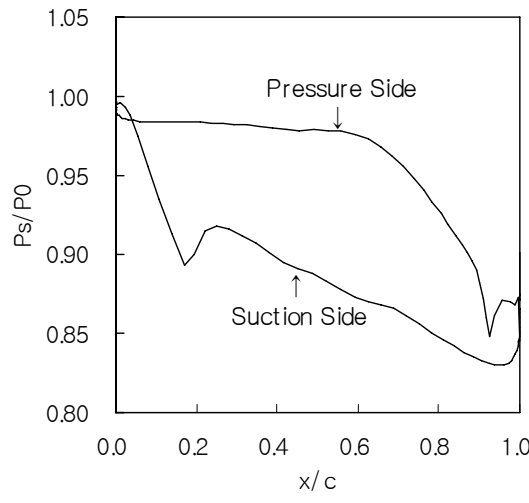

(b) Static pressure on vane

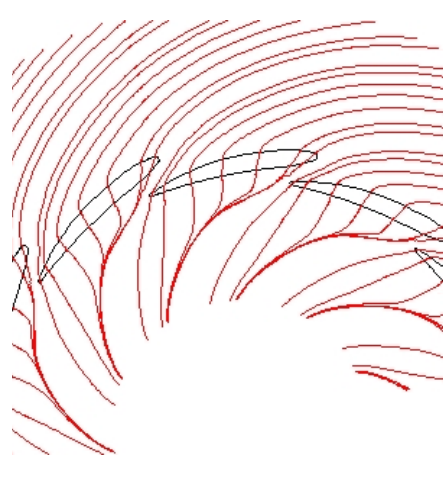

(c) Streamline passing through clearance 

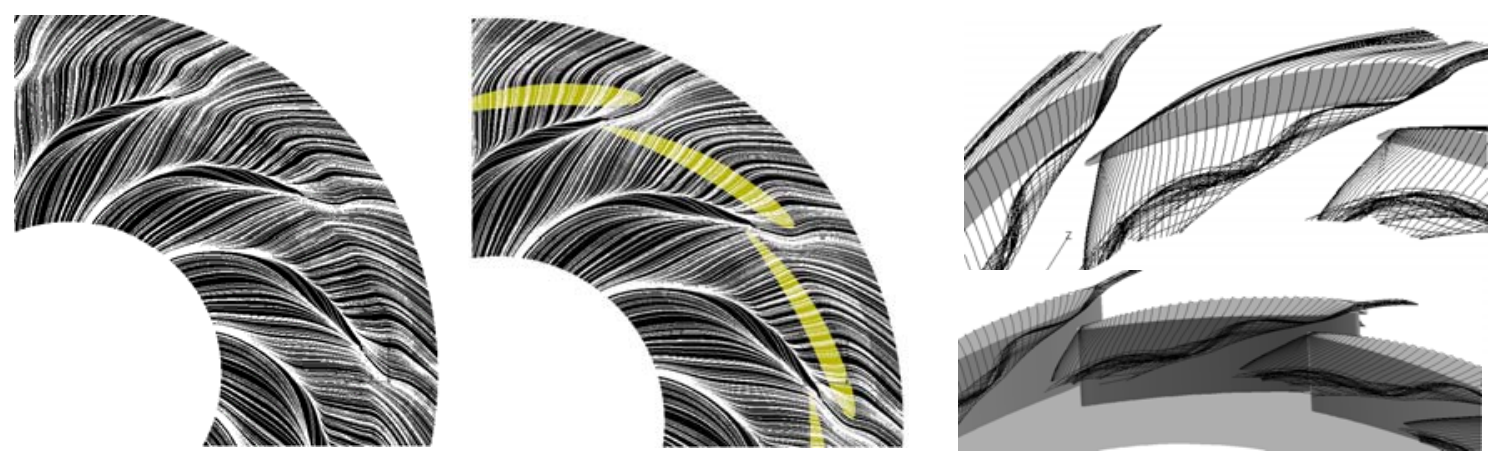

$\begin{array}{llll}\text { (d) Limiting streamline at shroud side } & \text { (e) Limiting streamline with vanes } & \text { (f) Streamline near the shroud }\end{array}$

Fig. 4 Calculated result (Smallest opening)
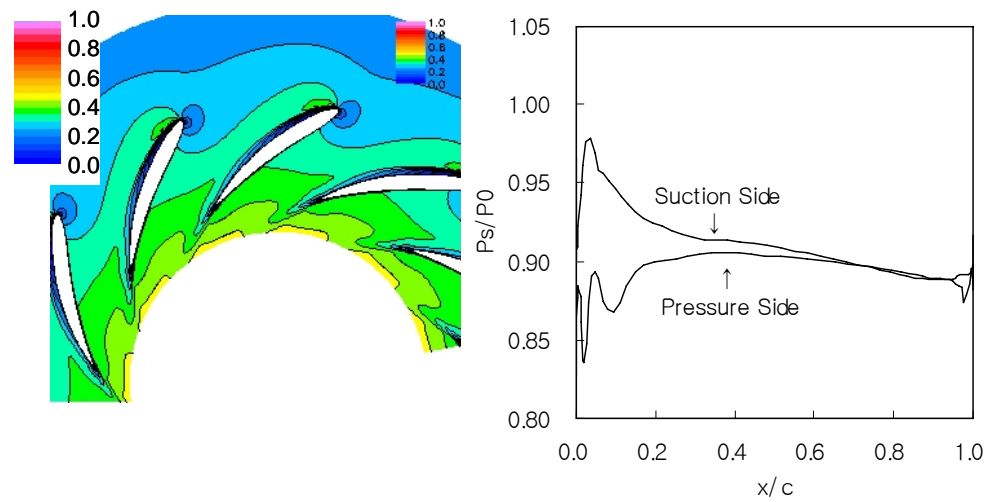

(a) Mach number distribution

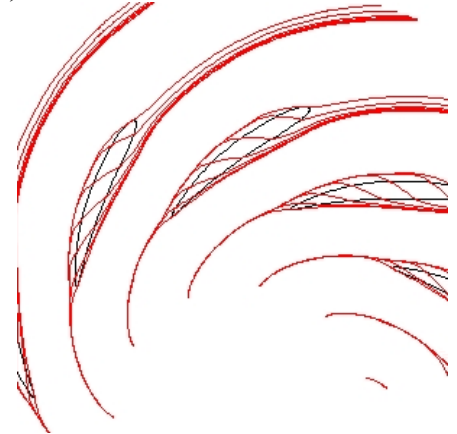

(b) Static pressure on vane

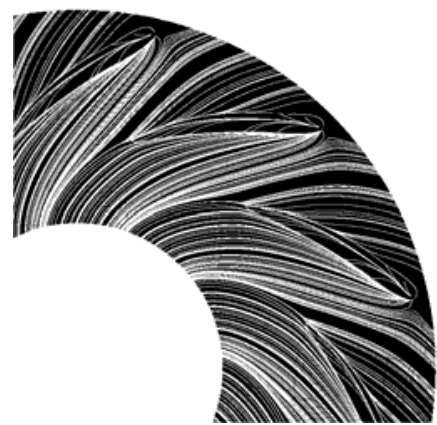

(c) Streamline passing through clearance (d) Limiting streamline at shroud side

Fig. 5 Calculated result (Largest opening)

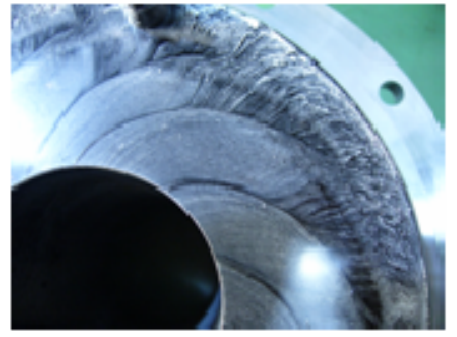

Shroud side (with clearance)

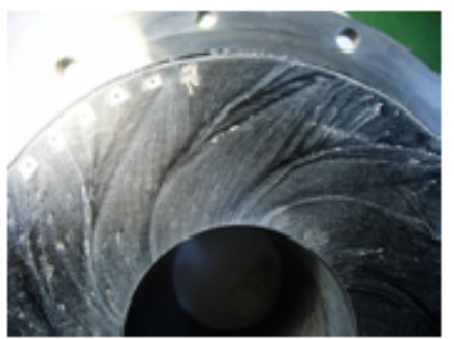

Shroud side (with clearance)

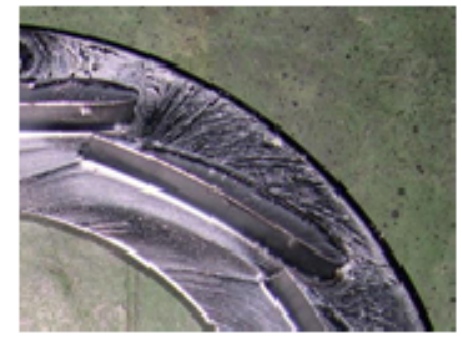

Hub side (with clearance)

(a) Smallest opening

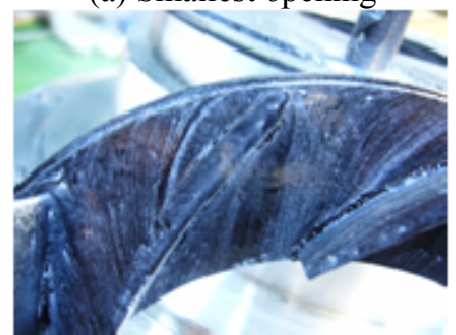

Hub side (with clearance)

(b) Largest opening

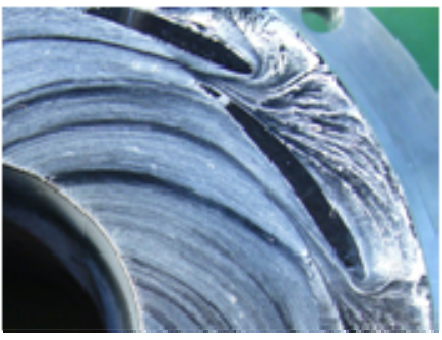

Shroud side (without clearance)

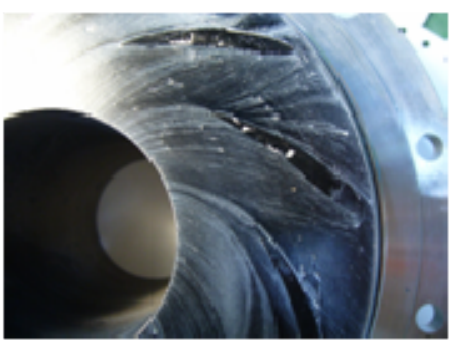

Shroud side (without clearance)

Fig. 6 Results of oil flow visualization 
Figure 7 shows the test results of the smallest opening. It shows the flow angle (measured from radial direction) and radial velocity $\mathrm{Cr}$ (inward flow is negative). $\theta$ indicates measuring position in the circumferential direction. The horizontal axis shows the spanwise position, 1.0 for the shroud side and 0.0 for the hub side. For the flow field measured, the flow angle is small near the shroud wall (radial velocity is high) and the flow angle at the mid-span portion is large (radial velocity is low). Figure 8 shows the flow angle and radial velocity obtained by circumferentially mass averaging the results of CFD analysis and measurement. These are the results of measurement and analysis of the nozzle with the clearance. As both results agree qualitatively, it can be considered that the measurement and CFD analysis results capture the feature of the flow field to some extent. The velocity distribution shown in Fig. 8 is considered to be formed as follows.

In case of the smallest opening, the main flow is turned in the circumferential direction by the nozzle, and the flow field with high circumferential velocity is formed. In this flow field, a pressure gradient occurs from the outer radius to the inner radius as to balance with the centrifugal force due to the high circumferential velocity. Since the circumferential velocity within the boundary layer is smaller than that in the main flow, the flow in the boundary layer is turned in the radial direction by this pressure gradient. For this reason, the flow angle decreases near the wall and the radial velocity near the wall increases. As a result, the flow passing near the mid-span decreases and the area decreases towards the downstream, but near the mid-span, the velocity component in the radial direction decreases. If the clearance exists, the flow passing through the clearance is not restricted by the nozzle vane, and so the flow angle near the wall surface on the side with the clearance (shroud side) further decreases and the velocity component in the radial direction increases.

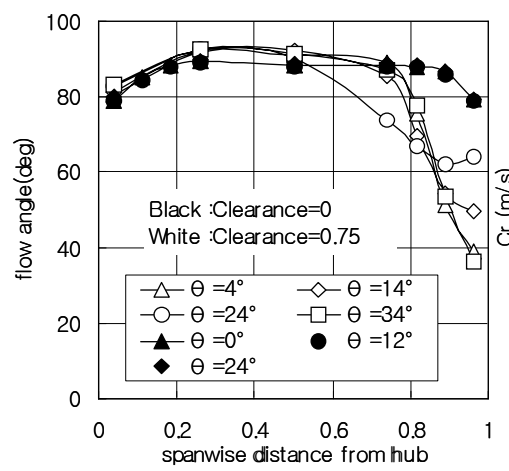

(a) Flow angle distribution

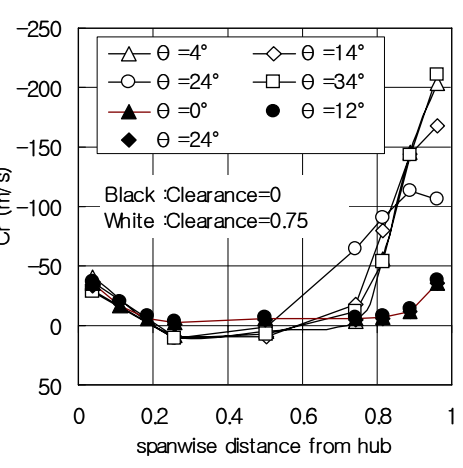

(b) Radial velocity distribution Fig. 7 Measurement result (Smallest opening)

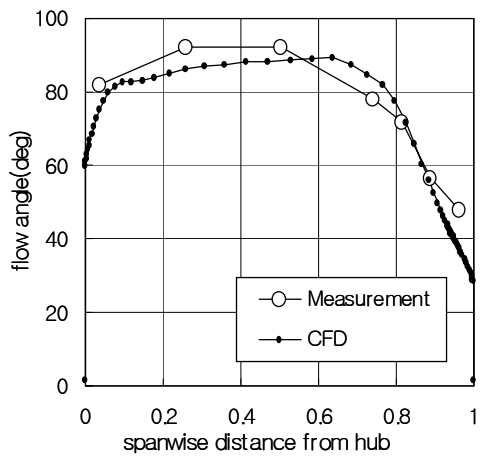

(a) Flow angle distribution

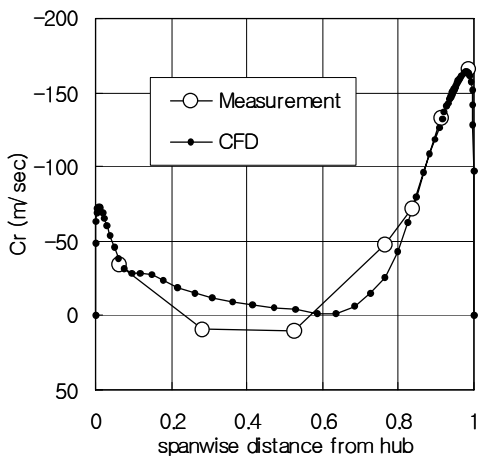

(b) Radial velocity distribution

Fig. 8 Comparison of CFD with measurement (Smallest opening)

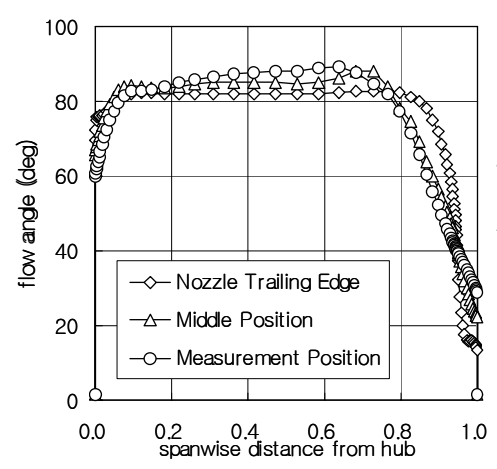

(a) Flow angle distribution

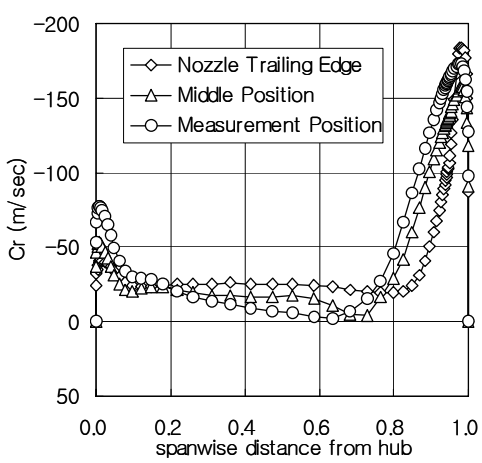

(b) Radial velocity distribution

Fig. 9 Computed flow angle and radial velocity at different positions ( Smallest opening ) 
analytical results when the clearance exists. As described above, it can be confirmed that as the radius decreases (approaching the measuring position), the radial velocity of the main flow decreases. Figure 10 shows the flow angle and total pressure distribution, which is divided by $\mathrm{P} 0$, on the cross section of the measuring position when the clearance exists. The outer frame of the figure shows for 2 pitches of nozzle horizontally, and the upper part is for the shroud and the lower part for the hub. On the shroud side with clearance, the effect of leakage flow appears in the entire pitch direction. On the shroud side, a low total pressure area surrounded by the concentric curves exists. It is considered that this area is generated by the tip leakage vortex. The wake shedding from the nozzle trailing edge to the downstream of the vane tends to diffuse because the flow angle is large and the fluid path becomes long. Figure 11 shows the total pressure distribution at the nozzle trailing edge, $2 \mathrm{~mm}$ and $4 \mathrm{~mm}$ downstream from the trailing edge, and measuring position that is located at $12.8 \mathrm{~mm}$ downstream from the trailing edge. It can be seen that the wake diffuses near the nozzle trailing edge and the effect of the leakage vortex soon becomes dominant.

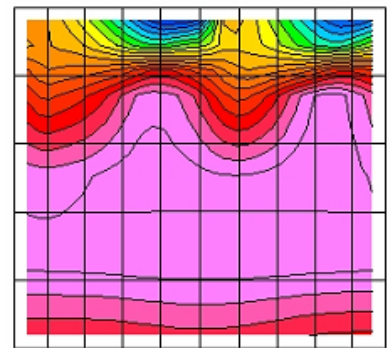

Measurement

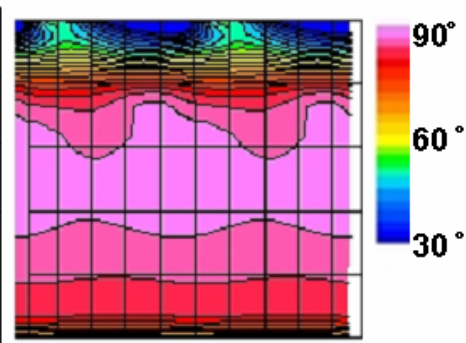

CFD

(a) Flow angle

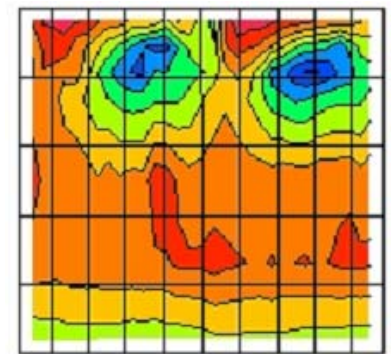

Measurement

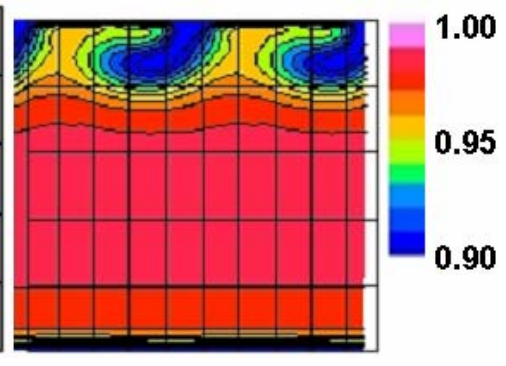

CFD

(b) Total pressure

Fig. 10 Flow angle and total pressure distribution (Smallest opening)

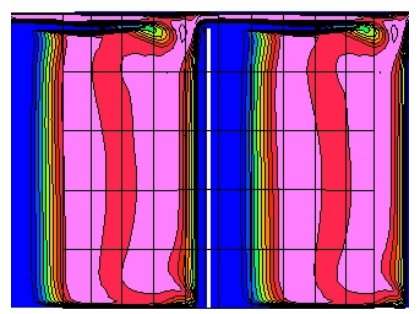

(a) Nozzle trailing edge

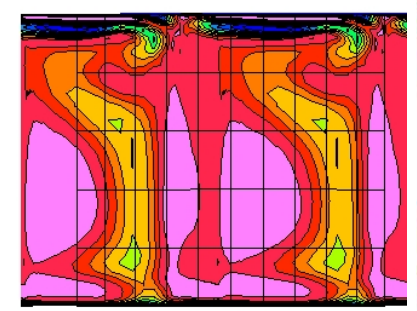

(b) $2 \mathrm{~mm}$ downstream

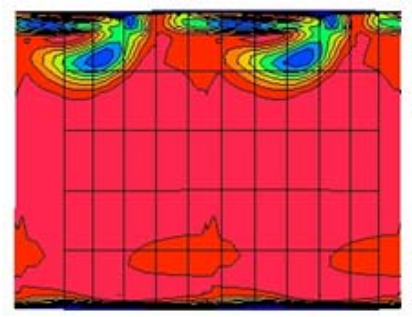

(c) $4 \mathrm{~mm}$ downstream

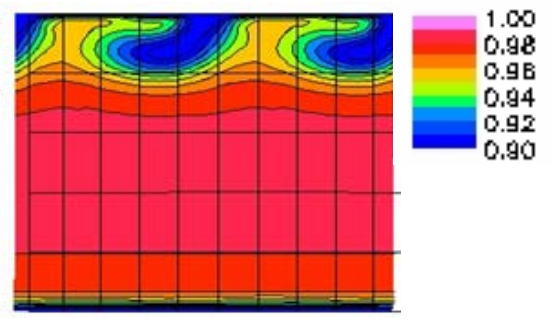

(d) Measuring position

from nozzle trailing edge from nozzle trailing edge

Fig. 11 Total pressure downstream of nozzle trailing edge

Figure 12 shows the average flow angle of the largest opening and average radial velocity. These are measurement and analysis results when the clearance of the nozzle vane exists. The results of CFD capture the characteristics of the measurement results, confirming that the measurement results and the CFD analysis are useful when discussing the flow field in the nozzle. Figure 13 shows the flow angle and radial velocity at each radial position that were obtained through the CFD analysis when assuming the clearance exists. The radial velocity increases as the radius decreases. Figure 14 shows the flow angle on the cross section of measuring position and total pressure distribution when the clearance exists. Since the area where the angle change occurs is almost the same on the hub side and shroud side, it can be judged that the effect of leakage flow on the flow field is small. In the total pressure distribution, a band-like low total pressure area exists from the hub to the shroud. In case of the largest opening, the measuring position is adjacent to the nozzle trailing edge and the flow angle is much smaller compared with the smallest opening, and hence it is considered that the strong effect of the wake appears.

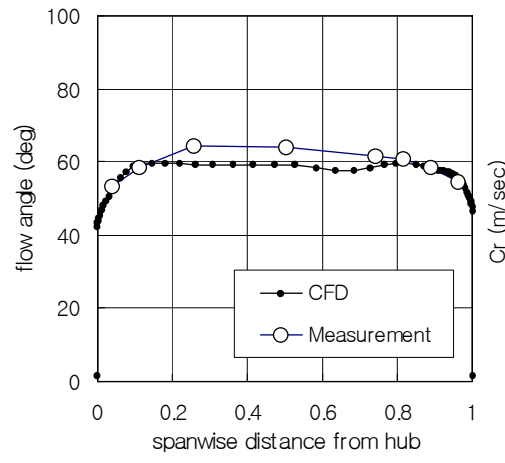

(a) Flow angle distribution

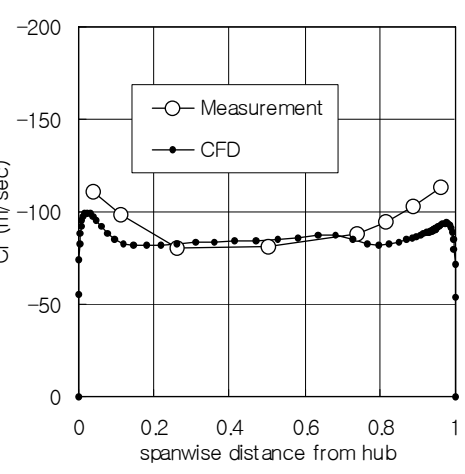

(b) Radial velocity distribution

Fig. 12 Comparison of CFD with measurement (Largest opening) 


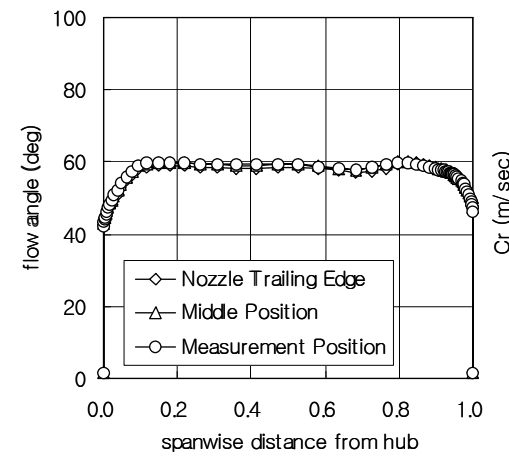

(a) Flow angle distribution

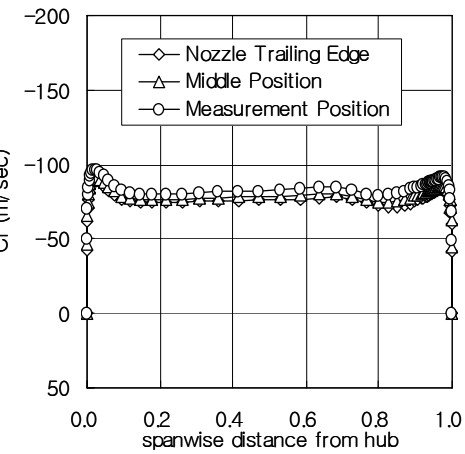

(b) Radial velocity distribution

Fig. 13 Computed flow angle and radial velocity at different positions (Largest opening)

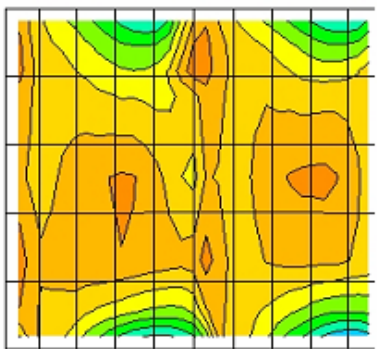

Measurement

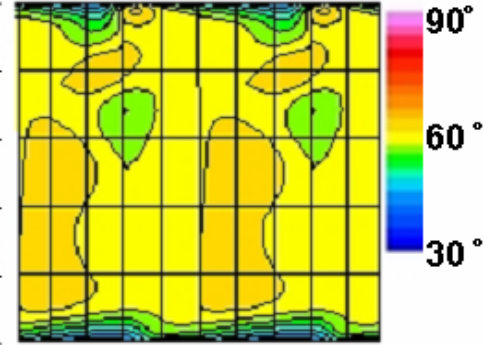

CFD

(a) Flow angle

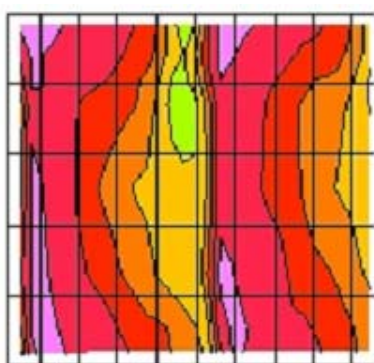

Measurement

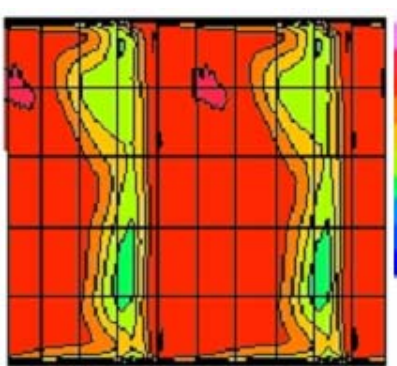

CFD

(b) Total pressure

Fig. 14 Flow angle and total pressure distribution (Largest opening)

\section{Calculation of Flow Fields in Nozzles with Actual Clearance}

The nozzle whose vane clearance is 2.5 times larger than that of the actual variable area nozzles is discussed in the previous section. The calculated results of the flow fields in the variable area nozzles with the actual vane clearance are shown in this section. The sum of clearance was $0.30 \mathrm{~mm}$. Hub and shroud side were provided with the clearance of $0.15 \mathrm{~mm}$ each. Figure 15 and Fig.16 show the calculated results for the case of the smallest opening and the largest opening respectively. Both figures show the streamline passing through the nozzle clearance and the total pressure distribution at the nozzle exit. Total pressure is dived by the scroll inlet total pressure. These calculated results ensure that the discussions in the previous section are accepted by the actual variable area nozzles.

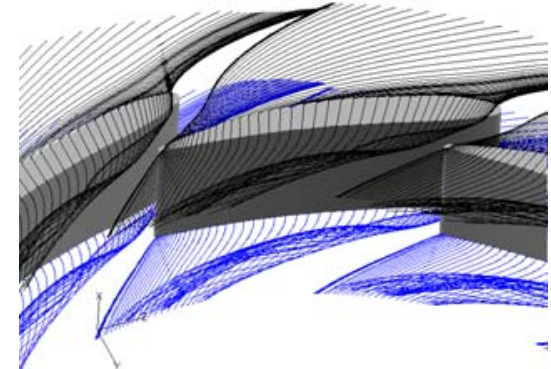

(a) Streamline passing through clearance

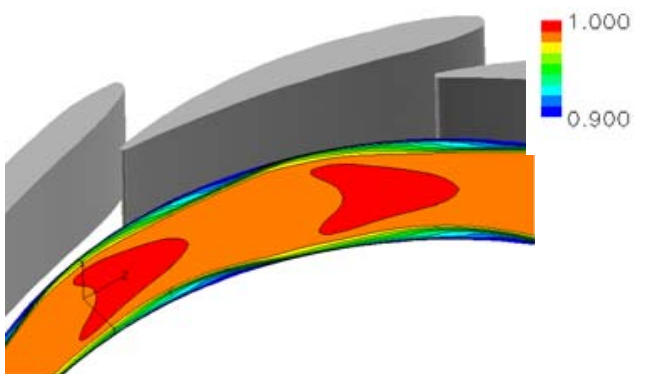

(b) Total pressure distribution

Fig. 15 Calculated result (Smallest opening)

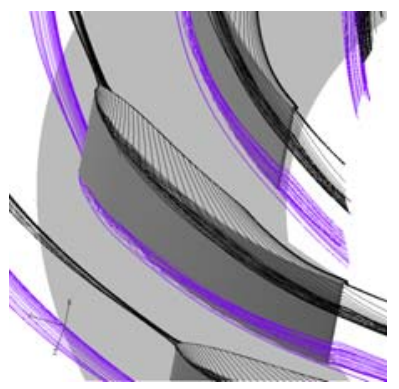

(a) Streamline passing through clearance

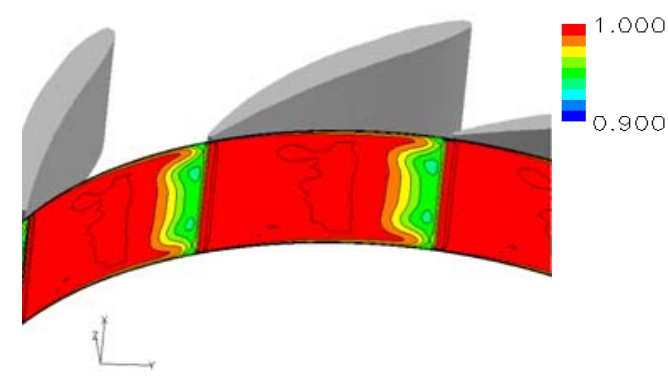

(b) Total pressure distribution

Fig. 16 Calculated result (Largest opening)

\section{Relation Between Leakage Flow Through Nozzle Vane Clearance and Nozzle Performance}


The leakage flow rate through the clearance of the nozzle vane was investigated with the results of CFD assuming that the flow crossing the center of the computational surface of the nozzle vane was the leakage flow. Figure 17 shows the relation between the ratio of the clearance (c) to the vane height $\left(b_{2}\right)$, and the ratio of the leakage mass flow rate (Wc) to the total mass flow rate $(\mathrm{W})$, as to the nozzle vanes shown in Table 1 and Fig. 2. Both hub and shroud side were provided with the clearance as in case of actual vanes and the equal clearance was applied to both sides. The calculated leakage flow rate is the total for both hub and shroud side. As shown in the previous section, the leakage flow increases as the nozzle opening decreases or the vane setting angle increases. The ratio of the leakage flow rate to the total flow rate is roughly proportional to the clearance at the same nozzle opening.

Figure 18 shows the relations between the clearance and the pressure loss coefficient, which is defined as the ratio of the total pressure decrement between the leading edge and trailing edge of the nozzle vane to the dynamic pressure at the trailing edge of the nozzle vane. Two different averaging methods were applied to derive the properties that were required to calculate the pressure loss coefficient. One was mass averaging and the other was mixed out averaging. The pressure loss coefficient derived from the mass average properties is $\xi \mathrm{m}$ and that from the mixed out average properties is $\xi \mathrm{x}$ in Fig. 18. Appendix-2 describes the definitions of averaging method, $\xi \mathrm{m}$ and $\xi \mathrm{x}$.

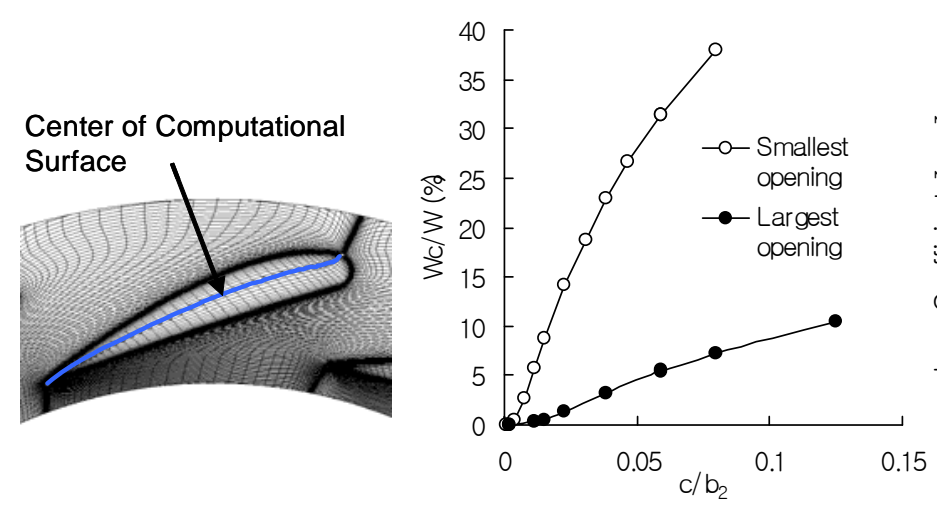

Fig. 17 Leakage flow rate

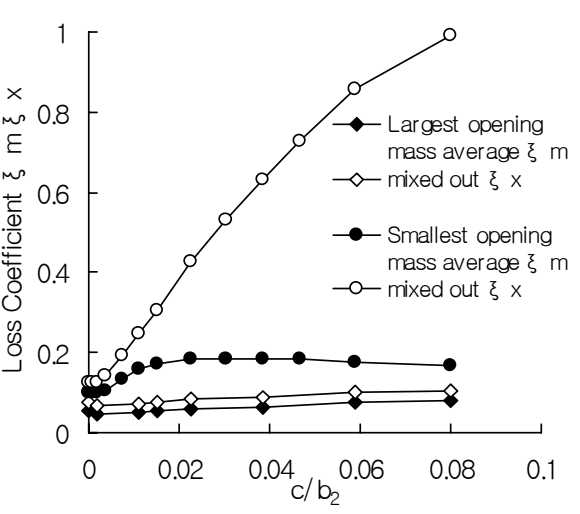

Fig. 18 Pressure loss Coefficient

For the largest opening, $\xi \mathrm{m}$ and $\xi \mathrm{x}$ are almost independent of the clearance. The loss due to the nozzle clearance can be neglected. In case of the smallest opening, $\xi \mathrm{m}$ and $\xi \mathrm{x}$ are constant to $\mathrm{c} / \mathrm{b}_{2}$ of 0.002 or less. Although the further increase of $\mathrm{c} / \mathrm{b}_{2}$ increases $\xi x$ monotonously, $\xi \mathrm{m}$ becomes constant with respect to $\mathrm{c} / \mathrm{b}_{2}$ of more than 0.015 . Figure 19 shows the circumferentially mass averaging total pressure and radial velocity distribution near the wall at the trailing edge of the nozzle vane. $y$ is the distance from the wall. The position where the total pressure is local minimum value is assumed to be the center of leakage vortex and the distance between this position and the wall can be the approximation of the radius of the leakage vortex. The radius of the leakage vortex increases as the clearance increases and the region affected by the leakage vortex enlarges. However this region is confined within about $12 \%$ of the passage height up to $\mathrm{c} / \mathrm{b}_{2}$ of 0.078 . In addition, the leakages flow increases the radial velocity near the wall and the product of the mass flow rate and the total pressure does not necessarily decrease above region. Hence, the increase of $\xi \mathrm{m}$ settles down at a certain $\mathrm{c} / \mathrm{b}_{2}$. On the other hand the non-uniform flow caused by the leakage vortex increases $\xi \mathrm{x}$. The difference between $\xi \mathrm{x}$ and $\xi \mathrm{m}$ is considered as the mixing loss downstream of the nozzle vane. The existence of the nozzle clearance grows the non-uniformity of the flow distribution. Figure 18 suggests the importance of taking the mixing loss into account to predict the nozzle performance at the small opening.

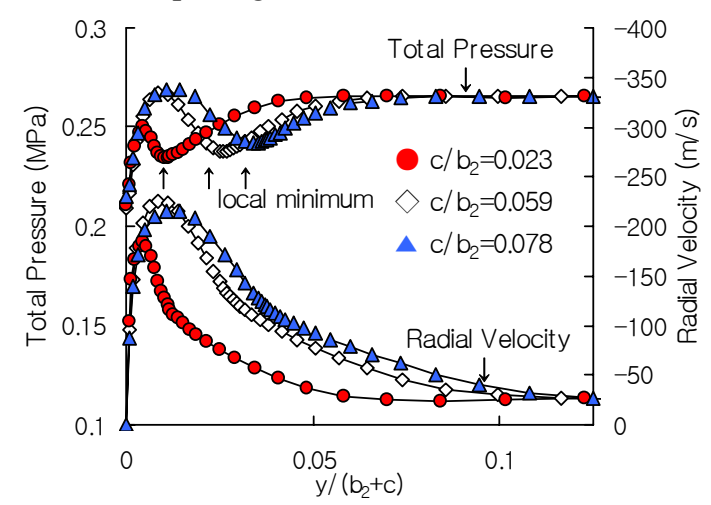

Fig. 19 Total pressure and radial velocity distribution at nozzle vane trailing edge

\section{Conclusion}

The flow field downstream of the variable area nozzle for radial turbine was investigated and the effect of the clearance of the nozzle vane, which is indispensable to move the vane, on the nozzle performance was investigated. The following results were obtained.

1. In case of the smallest opening of the nozzle vane, the effect of the leakage flow through the nozzle vane becomes dominant in the flow field. Due to the leakage vortex produced, non-uniformity of the total pressure and flow angle in the entire pitch 
direction near the wall is generated. This non-uniformity of the flow field causes the mixing loss downstream of the nozzle vane and deteriorates the nozzle performance.

2. In case of the largest opening of the nozzle, the effect of the leakage flow on the flow field is small. In the pitch direction, there exists a low total pressure area that is considered to be caused by wake. It is a flow field where the effect of wake is dominant. The effect of the clearance of the nozzle vane on the nozzle performance is negligible.

3. The leakage flow increases as the nozzle opening decreases or the vane setting angle increases. The ratio of the leakage flow rate to the total flow rate is roughly proportional to the clearance at the same nozzle opening.

4. For the largest opening, the pressure loss coefficient which is derived from the mixed out properties is almost independent of the nozzle clearance. The loss due to the nozzle clearance can be neglected. In case of the smallest opening, the pressure loss coefficient which is derived from the mixed out properties is almost proportional to the nozzle clearance.

\section{Appendix}

\section{Appendix-1}

Figure A-1 shows the schematic diagram of the static pressure distribution on the surface A and B. If the incidence angle at the vane leading edge is small, the flow on the surface of B goes through the nozzle throat at first and then that of A enters into the nozzle throat. Hence this paper defined the surface of B as suction side and that of $A$ as pressure side.

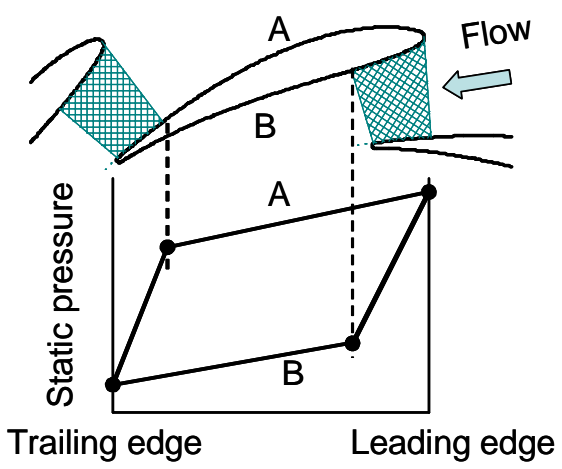

Fig. A-1 Definition of suction and pressure surface

\section{Appendix-2}

\section{(1) Mixed out average}

The mixed out average property is defined as the property that would exist after full mixing at the constant area [8]. Hence the mixed out average total pressure is reduced by the loss which is generated by the mixing process of non-uniform flow.

The mixed out property is derived by the continuity, momentum and energy equation.

The continuity equation is

$$
\int \rho u d A=\rho_{x} u_{x} A
$$

The momentum equations are

$$
\begin{aligned}
& \int\left(\rho u^{2}+p\right) d A=\left(\rho_{x} u_{x}^{2}+p_{x}\right) A \\
& \int \rho u v d A=\rho_{x} u_{x} v_{x} A \\
& \int \rho u w d A=\rho_{x} u_{x} w_{x} A
\end{aligned}
$$

The energy equation is

$$
\int \rho u\left(C_{p} T+\frac{u^{2}}{2}\right) d A=\rho_{x} u_{x}\left(C_{p} T_{x}+\frac{u_{x}^{2}}{2}\right) A
$$

The equation of state is

$$
p_{x}=\rho_{x} R T_{x}
$$

$\rho, \mathrm{p}$ and $\mathrm{T}$ are static density, static pressure and static temperature respectively. $\mathrm{u}$ is velocity perpendicular to area A. v, and $\mathrm{w}$ are velocity perpendicular to $\mathrm{u}$ and $\mathrm{v}$ is perpendicular to $\mathrm{w}$. Subscript $\mathrm{x}$ shows the mixed out average. There are six unknown quantities, $\rho_{\mathrm{x}}, \mathrm{p}_{\mathrm{x}}, \mathrm{T}_{\mathrm{x}}, \mathrm{u}_{\mathrm{x}}, \mathrm{v}_{\mathrm{x}}, \mathrm{w}_{\mathrm{x}}$ and six equations are available. Hence unique solution can be obtained.

\section{(2) Mass average}


The mass average is the average weighted by the mass flow. No mixing loss is considered, even if the non-uniformity of the flow is remarkable.

The mass average property of $\mathrm{X}$ is defined as follows. Subscript $\mathrm{m}$ shows the mass average.

$$
X_{m}=\frac{\int X \rho u d A}{\int \rho u d A} .
$$

(3) Pressure loss coefficient $\xi \mathrm{m}$ and $\xi \mathbf{x}$

The loss coefficient, $\xi \mathrm{m}$, which is derived from the mass average properties, is

$$
\xi_{m}=\frac{P t_{1, m}-P t_{2, m}}{P t_{2, m}-P_{2, m}}
$$

The loss coefficient, $\xi x$, which is derived from the mixed out average properties, is

$$
\xi_{x}=\frac{P t_{1, m}-P t_{2, x}}{P t_{2, x}-P_{2, x}}
$$

Pt and P are total pressure and static pressure respectively. Subscript 1 shows leading edge of the nozzle vane and 2 shows the trailing edge of the nozzle vane. Subscript $\mathrm{m}$ and $\mathrm{x}$ show the mass average property and the mixed out average property respectively, which are explained above.

\section{References}

[1] P. L. Meitner and A. J. Glassman, 1980, "Loss Model for Off-Design Performance Analysis of Radial Turbines with PivotingVane Variable-Area", SAE Technical Papers 801135

[2] D. Flaxington, D. T. Szczupak, 1982, "Variable area radial -inflow turbine", Turbocharging and Turbochargers, C36/82, IMechE, pp. 55-62

[3] Y. Okazaki, N. Matsudaira et al., 1986, "A case of variable geometry turbocharger development", Turbocharging and Turbochargers, C111/ 86, IMechE, pp. 191-195

[4] K. Matsumoto, Y. Jinnai et al., 1998, "Development of variable geometry turbocharger for Diesel passenger car", $6^{\text {th }}$ International Conference on Turbocharging and Air Management Systems, C554/005/98, IMechE, pp. 329-346

[5] H. Hayami, Y. Hyun et al., 1987, "Flow field in outlet of variable nozzle for radial turbine", The Report of the Research Institute of Industrial Science, Kyushu University Report, No. 82, pp. 149-158

[6] Y. Senoo, M. Yamaguchi, Y. Hyun and H. Hayami, 1987, "The influence of tip-clearance on the performance of nozzle blades radial turbines", JSME International Journal, Vol. 30, No. 264, pp. 929-935

[7] Y. Hyun, Y. Senoo, M. Yamaguchi and H. Hayami, 1988, "The influence of tip clearance on the performance of nozzle blades radial turbines (Experimental and performance prediction at three nozzle angles)", JSME International Series 2, Vol.31, No.2, pp.258-262

[8] E. M. Greitzer, C. S. Tan, M. B. Graf, 2004, “Internal Flow Concept and Applications”, Cambridge University Press, pp. 244pp. 258 